\title{
Determination of the Elements of Architecture Students' Readiness to Conduct Professional Activities
}

\author{
https://doi.org/10.3991/ijep.v11i2.18431 \\ Olga Akimova ${ }^{\bowtie}$, Evgenij Dorozhkin, Nikolay Chapaev \\ Russian State Vocational Pedagogical University, Yekaterinburg, Russia \\ akimova_olga_bor@mail.ru \\ Anna Kiseleva \\ Ural State University of Architecture and Art, Yekaterinburg, Russia \\ Alina Stroganova \\ Russian State Vocational Pedagogical University, Yekaterinburg, Russia
}

\begin{abstract}
The study is dedicated to requirements for the professional training of engineering specialists and the need to determine the significant aspects of their readiness to conduct professional activities. Focus on certain training aspects will make it possible to increase both the quality and the speed of specialist training, as well as contribute to their personal motivation. The purpose of the study is to identify the elements of architecture student readiness to conduct professional activities. The study took place at the Ural State University of Architecture and Art (Russia, Yekaterinburg); it involved 120 fourth and fifth year students of the Faculty of Architecture, as well as 12 faculty teachers and 154 graduates of different graduation years who have from 5 to 20 years of professional experience. Based on the analysis of available research on professional readiness and a preliminary participant survey, a number of elements of students' readiness for professional activities have been identified. The elements of students' readiness to conduct professional activities have been identified. The survey participants described the elements that they believed would most contribute to professional readiness: motivational-axiological (22\% of participants), informational-cognitive (18.8\% of participants), personality-reflexive (16.7\% of participants) and activity-oriented (13.4\%). The study can be useful for vocational education teachers to help them identify the influence of students' personal characteristics on the successful development of their readiness for professional activities.
\end{abstract}

Keywords - Readiness for professional activity, self-development, professional self-realization, motivation for a professional activity, architect

\section{$1 \quad$ Introduction}

The labor market need for competitive specialists makes the issue of students' professional readiness for future professional activities especially relevant. For the pur- 
poses of research, we define a specialist as a person with skills and psychological characteristics that allow him \her to adequately fulfill certain professional duties. The current social development stage imposes fundamentally new requirements for jobs, and therefore for the higher educational institutions involved in specialist training [1]. Having graduated from a higher educational institution, a specialist usually needs a lot of time to adapt to the conditions of their professional activity. Despite the fact that adaptation to the working environment occurs based on the knowledge and skills acquired at the university, the readiness to conduct professional activities is one of the major factors $[2,3]$.

The issue of developing the readiness of architecture students for professional activities is invariably relevant. This is explained by the contradiction between the labor market requirements, the demand for the professional and personal characteristics of the architect, and the available educational resources to resolve this problem [4,5].

The idea of purposeful higher education makes the issue of the readiness of architecture students to conduct professional activities relevant. Readiness should include two components, namely professional and general professional readiness. In addition to qualification requirements clearly determined by state standards, the readiness for professional activity of a modern architect includes intellectual competence, selforganization, self-regulation, and self-actualization [6].

A modern architect is a professional and an active labor market participant possessing basic knowledge and design skills, developed creative thinking, the ability to see design prospects, and focused on personal development. In addition, in the past few decades, the requirements for qualifications, competence, readiness for professional activity have significantly increased regardless of the direction of training. In accordance with this, educational institutions are developing vocational training methodologies based on innovative information technologies and interactive teaching methods. Examples of such methodologies include the Strengthened Technical Vocational-Education Program (STVEP), project-oriented teaching methods, the STEM methodology, which is becoming more widespread and includes many separate interesting methods for improving the quality of engineering education $[3,7,8]$. The introduction of information innovations in higher education is a challenge to the traditional structure of education. These technologies do not only complement available teaching methods, but also change all internal components of the education system, from the content to the management of the educational process.

Thus, $\mathrm{Su}$ and Cheng [9] discuss the role of gamification in improving student motivation and achievement. Wenglinsky [10] analyzes the results of the national assessment of education and concludes that the use of innovative educational technologies most effectively affects student training, which often leads to some unexpected results. Hénard [11] notes that students' aspirations have changed following developments around the world in terms of economic models undergoing or benefiting from globalization and facing new challenges like massive unemployment in certain countries. The massification of higher education has also given students overwhelming choice and possibilities; there are more education models than ever before (e.g, distance learning and modularisation, international mobility). Perez-Sanagustin et al. [12] analyzed the contribution of innovative technologies to secondary and higher 
education and noted their positive impact on further professional activities of specialists.

The broader range of training opportunities has different set of tools and limitations in different countries and is not always directly related to work experience. Slastenin and Kashirin [13] note that Russian graduates experience difficulties in fulfilling their professional responsibilities. There is a mismatch between the professional activity model developed by students at university and the real situation in which they have to start their professional activity. The reason for this may be the dominance of the information component in the professional training of students to the detriment of the development of student readiness to solve real life problems [14].

Student readiness to conduct professional activities will contribute to effective innovative behavior in modern socio-economic conditions and the performance of specific work in accordance with the established requirements of the employer. This will encourage students to use the acquired knowledge in professional activities [15].

Social demand determines what activities a person should engage in after graduating from an educational institution to meet the needs of the society, while the need for self-actualization and realization of professional aspirations of the person is not always satisfied. In these conditions, the task of the educational institution is not only to provide innovative enterprises and companies with personnel but also to create conditions to promote a more adequate student awareness of the ways of their personal and professional development during the period of studies, increase their psychological stability, self-regulation, self-organization and creative self-development taking into account the fact that the readiness for professional activity is determined by the individual specificity of personal needs, the psychophysiological peculiarity of student disposition, the applied nature of abilities, as well as social and personal stimulation.

Thus, the research problem is relevant and can be considered in the context of improving the quality of vocational education and training; the issue is discussed as the fact that students develop an integral structure of knowledge and hierarchical levels of their professional relevance. There is a focus on creative self-development; psychological resistance to stressful factors is fixed, self-confidence is gained, and communication skills are improved. This increases customer and consumer satisfaction with the quality of training. Personal achievements of students in their career increase the external assessment of the university activities.

Further section 2 is devoted to the Literature review of the works related to the problem under study; section 3 contains a description of the Research Methods and Materials; section 4 details and analyzes the research Results; section 5 presents Discussion and section 6 contains Conclusions with a short summary of the findings and findings of the study.

\section{Literature Review}

It should be noted that the concept of "readiness" is being actively studied in professional pedagogy in the context of different specialist training. The researchers point out that the concept of readiness was introduced at the beginning of the twenti- 
eth century in connection with the need to model the activity of a person in various spheres of life [16]. At the same time, readiness as a potential state of the specialist is considered both as a theoretical problem [17] and a practice-oriented approach [18].

There are a few major scientific approaches to defining the concept of readiness. Psychological approach considers readiness as a personal characteristic that implies the ability to adapt and self-regulate behavior and development [6]; externally, this is the process and the result of skill development [19]; mentally, this is the disposition, actualization and adaptation of personal capabilities to perform successful actions at the given moment [20]. Pragmatist approach defines readiness as an integral manifestation of all personality aspects that help the person perform their responsibilities, including professional ones [21]. Pedagogical approach describes readiness as a general characteristic of the development, training and education of a person in accordance with the requirements of society [22]. Professional-pedagogical approach defines readiness as a characteristic of the effectiveness of vocational training of various specialists $[23,24]$.

Thereafter, the concept of readiness was introduced in the activity theory and considered in connection with the emotional and volitional, intellectual, moral and psychological potential of the individual in future professional activity. Readiness is referred to as an indicator of self-regulation and adaptation at various stages and levels of mental processes that determine the behavior of an individual through the lens of the physiology of psyche and social behavior [14]. Readiness considered by some researchers as a manifestation of volitional qualities of a person, which are determined by the nature of the future professional activity and at the same time affect its specificity [25]. Readiness also can be considered as a mental state of the individual, which determines the potential activation of mental functions in future professional activities [26] and as a category of subjectivity that occurs as a result of new personal experience when developing professional readiness [27].

The analysis of numerous studies devoted to the issue of architecture students' readiness to conduct professional activities made it possible to determine the key approaches to its interpretation: the shift of education towards vocational training, emphasis on the development of technical skills in specific areas of professional activity [28]; turning an idea into a sustainable approach to work [29]; a learning management system that helps to reduce student's cognitive overload in the educational process [30]; personal and professional development of the subjects of education [31].

Some of the researchers define readiness as a psychological attitude which is the activity basis. Some scientists believe that "readiness" is the social attitude that determines the behavior of the individual. Other scholars note that readiness is equivalent to preparedness. Another group of researchers define readiness for professional activity as a combination of personal capabilities and the acquired experience of selfrealization [32].

Thus, there is no unambiguous definition. This is complicated by the fact that there are contradictions between the need to develop students' readiness for professional activity and the established practice of vocational training; professional environment and information educational environment in which vocational training takes place; cognitive needs of the individual and the ability of higher education to meet them. In 
order to resolve these issues, it is necessary, first, to identify trends and principles of the development of students' readiness for professional activity as the basis of their competitiveness in the labor market; secondly, to substantiate provisions that determine the structure of students' readiness for professional activity.

Thus, the analysis allowed us to conclude that architecture students' readiness for professional activity is a complex integrative structure, which reflects the development of professionally important qualities and abilities of a specialist, in particular their attitude to the professional activity.

\section{$3 \quad$ Materials and Methods}

\subsection{Research methods}

A concept and terminology analysis was carried out in order to clarify the concept of architecture students' readiness to conduct professional activities; the experience of effective training of architects was also studied and generalized. This made it possible to answer the research objective: to identify the elements of architecture students' readiness for professional activity and assess their impact among a specific audience of students. To determine the elements of architecture students' readiness for professional activity, a Content Analysis of a number of studies devoted to this issue was used. The questionnaire included definitions that, according to the cited works, allow one to identify the activity of these elements in the psychological picture of the respondent's professional readiness. The respondents were presented with a description of the corresponding element, as well as a set of questions to identify this element. Each participant had to identify one of the elements as prevailing in his personal activities. The elements are described in the first part of the Results section.

This study of the structure of the elements of readiness for professional activity is based on the existing primary definitions of such elements, obtained so far by other researchers. It uses the simplest descriptive statistics to obtain the primary results of assessing readiness elements using the criteria proposed by researchers.

\subsection{Research design and sample}

The research was conducted at the Ural State University of Architecture and Art (Russia, Yekaterinburg). It involved 120 fourth- and fifth-year students of the Faculty of Architecture (60 male and 60 female students aged 20-23); 12 faculty teachers (7 men aged 35-48 and 5 women aged 35-50); 154 graduates of different graduation years who have from 5 to 20 years of professional experience ( 87 men aged 29-60 years and 67 women aged 29-54).

The questionnaire was developed based on the concept analysis of the elements defining the concept of professional readiness based on the generalization of research by foreign and Russian authors [14,33-35]. The questionnaire was used to conduct a survey; the results obtained were statistically and analytically processed. 


\subsection{Research stages}

The study consisted of three stages. At the first stage, the analysis of available methodological approaches to the issue was carried out; at the second stage, the material on the research problem was studied and assessed; at the third stage, the architecture students' awareness of the issue of motivation and readiness was generalized to identify the structural components of the problem under study.

\subsection{Data analysis}

The analysis of the survey results was carried out on the basis of the determination of the elements of architecture students' readiness to conduct professional activities. The components are described in the Results section. To assess the questionnaire aimed at the determination of the structural elements of student readiness, the number of respondents who emphasized one of the elements identified during the study is used; 19 out of 286 participants could not decide on the dominant component.

\subsection{Survey}

The final survey to identify the structural elements of the architecture students' readiness to conduct professional activities involved students, graduates and teachers of the architecture and art university (286 participants). Some surveys involved specific social groups of participants (154 graduates; 120 students as described above).

\subsection{Research limitations}

This study does not take into account a number of additional factors that may influence student professional readiness. These factors may include belonging to certain social groups, family status, features of the training program or the content of courses and the teaching methods used, and even the state of the labor market and the intensity of development of this area of technology. The study involves architecture specialists from one Russian university; therefore, its results cannot be fully applied to a larger group of other engineering students. The study does not take into account gender, social origin, social status and age of the participants.

\subsection{Ethical issues}

All research participants were invited on the basis of voluntary consent; confidentiality of their participation was guaranteed. The participants filled in the questionnaire on the principle of anonymity, in printed or electronic form, as selected. No personal data were recorded or used for research purposes. 


\subsection{Statistical processing}

The survey results were processed in MS Excel included in Office 360. The processing of the survey results was aimed at determining the percentage of the number of participants who gave a particular answer to certain questions.

\section{$4 \quad$ Results}

Motivational-axiological component. Professionalism involves the full realization of the abilities and values of the individual as a professional, the identification and formation of one's own capabilities, the knowledge of one's own nature and the desire to develop professionally. This is a conscious and purposeful process of revealing one's own personality and individuality, realizing personal efforts, as well as developing personal and professional qualities in the career chosen. Motives determine the central position of a person; they directly affect the formation of readiness for professional activity, self-improvement, as well as the development and behavior of the individual [36]. The emphasis on axiology lies in the fact that it stimulates human behavior in any field of activity [37].

The informational-cognitive component of the readiness of architecture students to conduct professional activities, in addition to professional knowledge, includes: a) General knowledge that determines the general outlook and value orientations (knowledge of the basics of philosophy, politics, sociology, religious studies, law, technology, etc.), cultural outlook (knowledge of local history, literature, morality, ethics, aesthetics, culture, art, etc.), professional outlook (basic professional knowledge); b) Special knowledge focused on the implementation of professional skills: the history of the profession; the features and composition of professional skills, the key mechanisms for their implementation (stages, forms, methods, means, innovative technologies). The informational-cognitive element of readiness is implemented provided there are appropriate skills, which are embodied through the activity-oriented element of the readiness of architecture students to conduct professional activities.

The activity-oriented component consists of a system of professional skills. These include the ability to set professional goals and objectives, plan steps to achieve them, mastery of various professional methods, techniques and technologies; the ability to choose and use effective tools for collecting and assimilating information; the ability to independently work with literary sources; the ability to exercise self-control, selfanalysis and self-assessment of the results of professional activity; self-education; possession of volitional qualities, in particular perseverance, discipline in the process of completing educational tasks and achieving self-improvement goals, etc.

In addition, we believe that it is important to be able to see core values and achieve practical results in professional activities; to distinguish between goals-results and intermediate goals-means; to understand and correlate one's own capabilities with social requirements; to independently form, develop, and creatively transform the necessary professional qualities. These skills make the student a professionally competent and self-confident specialist. 
The personality-reflexive component of the readiness of architecture students to conduct professional activities involves, first of all, the focus on self-analysis and self-assessment of professional development. It characterizes the system of student needs for personal professional self-development, and value awareness of the need for the development of each quality to conduct professional activities in the future.

According to researchers, reflection (from the Latin "reflexio" - turning back) is the process of drawing attention to oneself and one's own consciousness, in particular, to the products of one's own activity and their rethinking. This is the self-knowledge of one's internal mental acts and states; a form of theoretical human activity aimed at realizing one's own actions and their laws [38].

Reflexive skills are considered as professional qualities of a specialist characterizing the ability to conduct self-analysis, focus on self-improvement and deeply immerse in life situations related to the performance of professional responsibilities. Reflexive skills help the specialist consciously refer to the need for professional selfimprovement (the development of personal and professional qualities, abilities, work methods), as well as control and evaluate it; the specialist demonstrates readiness to set and implement new goals and objectives.

The ability to reflect is inextricably linked with the development of professional and general professional knowledge and is specified by the totality of skills, in particular, it provides for the possession of reflexive skills in cognitive activity (selfobservation, self-analysis), self-assessment of one's own abilities and qualities; reflection of one's own professional activity; adequate self-assessment of one's own readiness for professional self-improvement.

The importance of reflexive skills in the professional activity of any specialist can hardly be overestimated. When acquiring new skills, the person becomes aware of the qualities of their personality (mental, volitional, moral, professional, etc.), character traits, and the specifics of interpersonal relationships. This allows the graduate to develop a holistic approach to their personality, professional knowledge, beliefs, and views; drives the need to periodically rethink one's own professional and personal qualities, critically review professional achievements, and set prospects for further self-improvement. The skills of self-observation, self-analysis, self-regulation, goalsetting, and self-programming turn the specialist into a subject of professional selfdevelopment. Thus, systematic reflexive activity contributes to the development of skills of the conscious implementation of professional activity and professional selfdevelopment.

\subsection{Argumentation of the structural elements of architecture students' readiness to conduct professional activities}

The components have been identified based on the analysis of the level of professional training of architecture students at the Ural State University of Architecture and Art. The research is based on the survey of fourth- and fifth-year students studying Architecture (bachelor's degree program).

There were 120 students that took part in the questionnaire and defined readiness for professional activity: according to 12 participants, this is a process of constant 
development and systematic improvement of knowledge; 16 students described it as independent acquisition of new knowledge by reading books, magazines, searching for information on the Internet and learning new things, and a person's aspiration to achieve better results, develop one's own personality and knowledge; 18 people defined it as a desire to be qualified and educated; 40 students believed that readiness is mastering new trends related to the profession chosen; 34 participants defined it as conscious and purposeful increase in the level of one's own professional activity.

One hundred and twelve students noted the importance of continuous professional self-improvement in modern conditions while 6 participants considered this issue to be irrelevant.

The overwhelming majority of respondents (118 students) positively assessed the amount of theoretical knowledge obtained at the University of Architecture and Arts; 1 person noted a lack of it and 1 participant expressed complete dissatisfaction.

The ability to develop and implement architectural projects in professional activities was assessed as follows: 87 participants answered in the affirmative, 4 respondents noted their inability and 29 students said they were able to perform and improve the technique of performance at a high level.

Based on the questionnaire results, the key motivational incentives of architecture students to conduct professional activities were determined (Fig. 1):

- Help other people and serve society (9 people)

- Be a highly-qualified and many-sided specialist (68 people)

- Improve professional knowledge and skills (17 people)

- Achieve the best professional results and become one of the best architects (14 people)

- Obtain high quality architecture education (12 people)

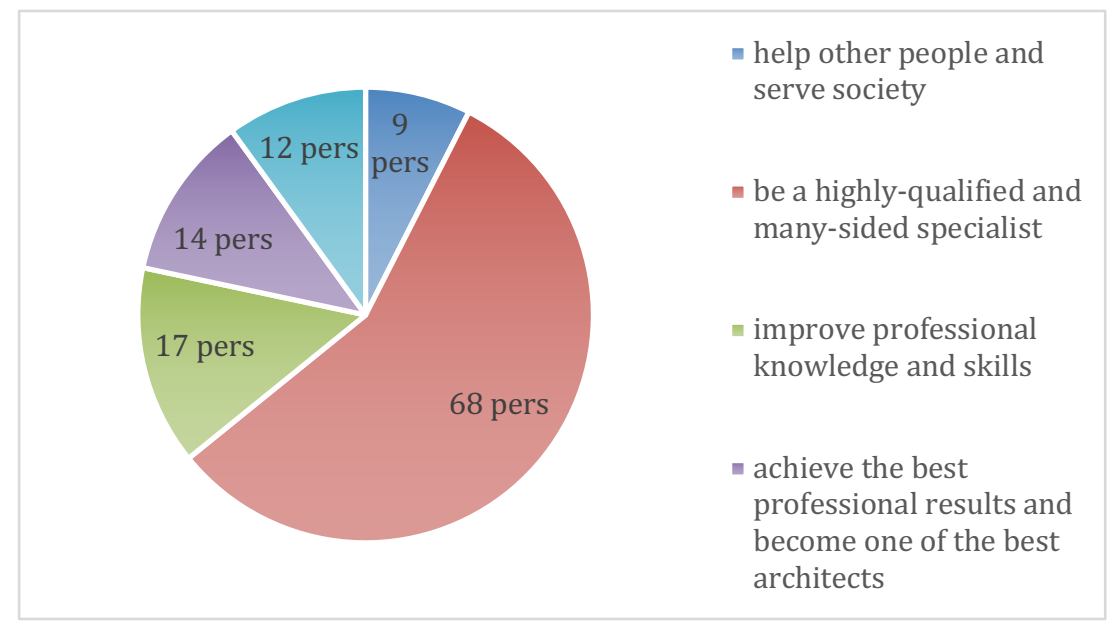

Fig. 1. Motivational incentives of architecture students to conduct professional activities 
The survey results showed that the concept of professional development is properly understood by 91 students while 21 students have misunderstanding of the concept of professional development and 8 people do not understand it at all. It is important that the majority of architecture students consider the process of professional development to be relevant for themselves in modern conditions.

We have also surveyed the architecture and art university graduates of different years of graduation that have professional experience from 5 to 20 years. They are highly organized and creative architects with high moral values and solid performance.

The overwhelming majority of respondents among graduates (134 out of 154 people) explained the high level of their professional development by the use of a wide range of ways and tools for self-improvement, which they independently mastered mainly during their professional activities.

One hundred and twenty-five participants noted their readiness to conduct professional activities after graduation while 29 people gave a negative answer; 148 people believe that they have become extremely competent.

Figure 2 shows the results of the final questionnaire aimed at the determination of the structural elements of the readiness of architecture students to conduct professional activities; the questionnaire involved students, graduates, and teachers of the university of Architecture and Art (286 people).



Fig. 2. The results of the final questionnaire aimed at the determination of the structural elements of the readiness of architecture students to conduct professional activities

Thus, based on the results obtained, we identified the elements of architecture students' readiness to conduct professional activities, which, in the opinion of the respondents, will contribute to the effective development of the readiness of architecture students for professional activities, namely, motivational-axiological (76 respondents out of 286), informational-cognitive (68 people); activity-oriented (41 people), personality-reflexive (53 people). 


\section{Discussion}

At a global level, the issue of developing professional readiness is considered in connection with two aspects of personnel training: psychological readiness to make decisions and solve real-life problems and professional readiness to acquire the necessary skills $[16,21,25,33,35]$. Most often researchers focus on the features of professional readiness manifestation in individual professions or analyze the experience of individual countries and higher educational institutions. In contrast to these studies, we tried to assess as fully as possible all components of readiness with due regard to psychological, professional and other aspects of student training.

In the Russian pedagogy of higher education, the phenomenon of "readiness" for professional activity is a key concept in the assessment of the results of professional training. The issue of developing the readiness of university students to conduct professional activities in the future is one of the most significant issues in modern Russian science [34]. The structure of student readiness for professional activity, according to Kulikova and Pronina [39], consists of cognitive, motivational and activityoriented components. This approach correlates with our definition of the structure of student activity but has been significantly expanded on the basis of knowledge gained in practical research.

According to Baltusite and Katane [33], the structure of readiness for professional activity is developed on the basis of two key components: psychological readiness and competence readiness. The researchers believe that professional activity readiness involves not only the development of personal qualities, but also describes the situation before the start of professional activity, as well as the result of student professional development during the period of study [33]. In our study, alumni also specifically emphasized the role of the number and variety of professional self-improvement tools used in their success. The relationship of these tools to the influence of the teacher and the university course, or only to the personal efforts of students, remains to be explored.

Ganicheva and Miruk [14] studied the development level of some components of psychological readiness, namely, the emotional attitude of psychology students to future professional activities, the orientation of the personality in communication, as well as the level of professional training motivation, and experimentally came to the conclusion that the revealed essence of readiness as mental formation characterized by internal forces of the student and the focus on meaningful activity ensures the success of professional activities. This study showed that the majority of students showed high confidence in their training and professionalism, but the sources of this confidence, as far as can be judged from the structure of readiness, were personal efforts. It should be noted that the development of students' readiness for future professional activity is ensured by the creation and implementation of a system of tasks aimed at self-perception; improvement of self-awareness skills; optimization of the emotional state; awareness of professional values and principles; and the development of professional confidence and predictive ability.

Aprile and Knight [35] are Western scholars who highlight learning based on practical activities and real-world decision making. The introduction of the STEM methodology, which is increasingly used in higher educational institutions, in engineering training is based on the basic practical training of the specialist. It should be noted 
that the majority of students used the structural elements of the readiness, which presuppose the presence of high cognitive and practically oriented activity (informationcognitive or activity-oriented etc.), which is consistent with the indicated study. At the early stage, training is based on the simulation of practical activities; when the necessary skills and experience are gained, the focus is shifted to practice [26].

Grus et al. [16] summarize a significant number of studies, analyze the phenomenon of professionalism as a cluster of skills and characteristics of the personal experience of specialists. The researchers point out that the characteristics of the personal experience of specialists are homogeneous. According to their research, professionalism is the result of the simultaneous effect of the necessary psychological components and skills. This approach closely correlates with the results of our study and the components of professional readiness may overlap with the content of the clusters of professionalism in the study mentioned above.

The research findings $[19,24]$ showed that there is no consensus on the structural components of professional activity readiness, which confirms the need to study the problem as a holistic phenomenon that characterizes the result of specialist training at a university. This is largely due to the fact that there is no unambiguous definition to the concept of "professional activity readiness." There are also significant differences in the definition and design of the concepts of professionalism and professional readiness. The theory of psychological readiness was developed in detail by Russian psychology [32]; however, globally, the concept is used in a broad sense [27]. The phenomenon is complex; it has certain functions, properties, and levels. The theory and practice of professional activity undergo significant changes due to changing social conditions and the development of technology.

\section{Conclusion}

The theoretical analysis allowed us to clarify that professional activity readiness is considered as a set of interrelated and interdependent psychological qualities that are expected to contribute to successful professional activity in any field and ensure the interaction of all its subjects. Based on the analysis of studies devoted to professional readiness, a number of structural components were identified; their significance and influence were assessed in the survey. The study involved 286 participants: students, teachers and graduates of the Ural State University of Architecture and Arts (Russia, Yekaterinburg).

The readiness of architecture students to conduct professional activities is a complex integrative structure which reflects the development of professionally important qualities and abilities of a specialist, in particular their attitude to the professional activity.

The survey participants described the elements that they believed would most contribute to professional readiness: motivational-axiological (26.57\% of participants), informational-cognitive $(23.78 \%$ of participants), personality-reflexive $(14.33 \%$ of participants) and activity-oriented (18.53\%).

Based on the generalization of various approaches to the structure of architecture students' readiness for professional activities, we determined the following components: motivational-axiological, aimed at revealing personality traits; informational- 
cognitive, which describes general knowledge that determines the outlook and value orientations; activity-oriented, which contributes to the development of a system of professional skills, including the ability to set professional goals and objectives, plan steps to achieve them, master the technologies of the chosen profession, as well as the ability to see life values and achieve specific practical results in professional activity; personality-reflexive, which implies the focus on self-analysis and self-assessment of one's own professional development.

Further research on the issue should be devoted to the study of the ways to develop architecture students' readiness to conduct professional activities based on active learning and the use of cloud technologies.

\section{$7 \quad$ References}

[1] Lubkov, A.V. (2020). Modern Problems of Pedagogical Education. The Education and Science Journal, 3(22): 36-54.

[2] Sikorskaya, G., Akimova, O., Dorozhkin, E., Yakhneeva, I. (2016). Noospheric pedagogy: The expansion of the humanitarian space of vocational and pedagogical education. International Journal of Environmental \& Science Education, 11(14): 6963-6975.

[3] Zinchenko, Y.P., Dorozhkin, E.M., Zeer, E.F. (2020). Psychological and Pedagogical Bases for Determining the Future of Vocational Education: Vectors of Development. The Education and science journal, 22(3): 11-35. https://doi.org/10.17853/1994-5639-2020-3$\underline{11-35}$

[4] Dorozhkin, E.M., Zeer, E.F., Shcherbina, E.Y. (2017). Training modernization strategy of the teachers of vocational education. Journal of Engineering and Applied Sciences, 12(S11): 9061-9067.

[5] Rughinis, R., Matei, S. (2015). Badge architectures as tools for sense-making and motivation in engineering education. International Journal of Engineering Pedagogy, 5(4): 55-63. https://doi.org/10.3991/ijep.v5i4.4957

[6] Abualoush, S., Masa'deh, R., Bataineh, K., Alrowwad, A. (2018). The role of knowledge management process and intellectual capital as intermediary variables between knowledge management infrastructure and organization performance. Interdisciplinary Journal of Information, Knowledge, and Management, 13: 279-309. https://doi.org/10.28945/4088

[7] Almetov, N., Zhorabekova, A., Sagdullayev, I., Abilhairova, Z., Tulenova, K. (2020). Engineering Education: Problems of Modernization in the Context of a Competence Approach. International Journal of Engineering Pedagogy, 10(6): 7-20. https://doi.org/10.3991/ijep.v10i6.14043

[8] Al-Bahi, A.M., Taha, M.A., Turkmen, N. (2013). Teaching and Assessing Engineering Professional Skills. International Journal of Engineering Pedagogy, 3: 13-20.

[9] Su, C.H., Cheng, C.H. (2015). A mobile gamification learning system for improving the learning motivation and achievements. Journal of Computer Assisted Learning, 31(3): 268-286. https://doi.org/10.1111/jcal.12088

[10] Wenglinsky, H. (2005). Technology and achievement: The bottom line. Educational Leadership, 63(4), 29-32.

[11] Hénard, F. (2016). Higher Education and Society: The Third Mission. In The CIQG International Quality Principles: Toward a Shared Understanding of Quality. CIQG Publication Series, S. Uvalić-Trumbić, Ed. Washington, DC: Council for Higher Education Accreditation, pp. 23-30. 
[12] Pérez-Sanagustín, M., Nussbaum, M., Hilliger, I., Alario-Hoyos, C., Heller, R.S., Twining, P., Tsai, C.C. (2017). Research on ICT in K-12 schools e A review of experimental and survey-based studies in computers \& education 2011 to 2015. Computers and Education, 104: A1-A15. https://doi.org/10.1016/j.compedu.2016.09.006

[13] Slastenin, V.A., Kashirin, V.P. (2006). Psychology and pedagogy: textbook, 4th ed. Moscow: Academiia.

[14] Ganicheva, I. A., Miruk, A.V. (2016). The development of students' psychological readiness for future professional activities. Modern studies of socialproblems, 3-2(59): 235-241.

[15] Khasanova, I.I., Kotova, S.S. (2018). Psychological Readiness of Secondary Vocational Education Teachers for Mastering New Activities in the Context of Professional Reorientation. The Education and science journal, 20(7): 147-167. https://doi.org/10.17853/19945639-2018-7-147-167

[16] Grus, C.L., Shen-Miller, D., Lease, S.H., Jacobs, S.C., Bodner, K.E., Van Sickle, K.S., Veilleux, J., Kaslow, N.J. (2018). Professionalism: A competency cluster whose time has come. Ethics \& Behavior, 28(6): 450-464. https://doi.org/10.1080 $\underline{10508422.2017 .1419133}$

[17] Bornstein, R.F. (2020). Supervising personality assessment. In Essentials of psychological assessment series. Essentials of psychological assessment supervision, A.J. Wright, Ed. Hoboken, NJ: John Wiley \& Sons, Inc., pp. 81-104. https://doi.org/10.1080 /00223891.2020.1757458

[18] Myhre, K., Moen, F. (2017). Does an Experience-Based and Practice-Oriented Approach in Coaching Education Influence Coaching Efficacy Positively? Uniped, 40(3): 235-248. https://doi.org/10.18261/issn.1893-8981-2017-03-05

[19] Yates, J. (2019). Book Review: Contemporary Theories of Career Development: International Perspectives. British Journal of Guidance \& Counselling, 1: 1-2.

[20] Schultz, D.P., Schultz, S.E. (2016). Theories of personality. Cengage Learning.

[21] Winter, I.A. (2010). Educational Psychology: Textbook for universities. Moscow: Logos Publishing Corporation.

[22] Belle, S. (2016). Organizational learning? Look again. The Learning Organization, 23(5): 332-341. https://doi.org/10.1108/tlo-01-2016-0007

[23] Bahar, S., Uysal, F.F. (2016). Factors Affecting Profession Choice and Profession Idealism of Logistics Associate Program Students. Presented at IBANESS Conference Series, Prilep, Republic of Makedonya.

[24] Cosser, M. (2019). Aspirations and horizons for action: student choice of profession in South Africa. In Post-school education and the labour market in South Africa, M. Rogan, Ed. Cape Town: HSRC Press, pp. 121-136.

[25] Blustein, D.L. (2017). The Psychology of Working: A New Perspective for Career Development. Career Planning \& Adult Development Journal, 33(2): 1-3.

[26] Trede, F., Macklin, R., Bridges, D. (2012). Professional identity development: a review of the higher education literature. Studies in Higher Education, 37(3): 365-384. https://doi.org/10.1080/03075079.2010.521237

[27] Saka, N., Gati, I. (2007). Emotional and personality-related aspects of persistent career decision-making difficulties. Journal of vocational behavior, 71(3): 340-358. https://doi.org/10.1016/i.jvb.2007.08.003

[28] Chandavarkar, P. (2007). The 'Background'in Bangalore; Architecture and Critical Resistance in a New Modernity. Architectural Design, 77(6): 78-83. https://doi.org/10.1002/ad.566 
Paper-Determination of the Elements of Architecture Students' Readiness to Conduct Professional...

[29] Sorensen, S. (2007). Architectural Representation and Emerging Technologies. Teaching and Experimenting with Architectural Design Transactions on Architectural Education, 35: 345-347.

[30] Lin, Y.A., Wen, M.H., Perng, Y.H., Hsu, I.T. (2016). Design, analysis and user acceptance of architectural design education in learning system based on knowledge management theory. Eurasia Journal of Mathematics, Science and Technology Education, 12(11): 28352849. https://doi.org/10.12973/eurasia.2016.02307a

[31] Mitina, L.M. (2014). Psychology of personal and professional development of subjects of education. Saint Petersburg: Nestor-History.

[32] Serova, O.E., Gostev, A.A. (2019). National Cultural Traditions of Russian Psychology How 'Creative Heritage'can Influence the Future of a Global Science. In 2nd International Conference on Education Science and Social Development (ESSD 2019). Atlantis Press, pp. 450-453. https://doi.org/10.2991/essd-19.2019.100

[33] Baltusite, R., Katane, I. (2014). The structural model of the pedagogy students' readiness for professional activities in the educational environment. Rural Environment. Education. Personality, 7: 29-41.

[34] Yakhina, Z.S., Yakovlev, S.A., Kozhevnikova, N.V., Nuretdinova, Y.V., Solovyeva, N.A. (2016). Practical Recommendations for University Graduates' Readiness Formation to Occupational Mobility. International Journal of Environmental and Science Education, 11(15): 7358-7367.

[35] Aprile, K.T., Knight, B.A. (2020). The WIL to learn: Students' perspectives on the impact of work-integrated learning placements on their professional readiness. Higher Education Research \& Development, 39(5): 869-882. https://doi.org/10.1080 /07294360.2019.1695754

[36] Wright, R.A. (2016). Motivation theory essentials: Understanding motives and their conversion into effortful goal pursuit. Motivation and Emotion, 40(1): 16-21. Chaturvedi, P. (2014). Axiological competences: The role of teacher training programme in strengthens it. IOSR Journal of Research \& Method in Education, 4(2): 19-23. https://doi.org/10.1007/s11031-015-9536-4

[38] Chupina, V.A., Fedorenko, O.A. (2018). Foresight technologies in the development of communicative reflection. In GCPMED 2018 - International Scientific Conference "Global Challenges and Prospects of the Modern Economic Development". Samara, Russian Federation.

[39] Kulikova, T.A., Pronina, N.A. (2018). Formation of the readiness of the future teacher for professional activities. Bulletin of Tomsk State Pedagogical University, 3(192): 84-90. https://doi.org/10.23951/1609-624x-2018-3-84-90

\section{Authors}

Akimova Olga Borisovna is a Doctor of Philological Sciences, Professor of the Department of Vocational Education and Training Methodology, Russian State Vocational Pedagogical University, Yekaterinburg, Russia.

Dorozhkin Evgenij Mikhailovich is a Doctor of Education, Professor at the Department of Vocational Education and Training Methodology, Russian State Vocational Pedagogical University, Yekaterinburg, Russia 
Paper-Determination of the Elements of Architecture Students' Readiness to Conduct Professional..

Chapaev Nikolay Kuzmich is a Doctor of Pedagogical Sciences, Professor of the Department of Vocational Education and Training Methodology, Russian State Vocational Pedagogical University, Yekaterinburg, Russia.

Kiseleva Anna Valerievna is a Senior Lecturer of the Department of Social and Humanitarian Sciences, Ural State University of Architecture and Art, Yekaterinburg, Russia.

Stroganova Alina Alexandrovna is a Master Student of the Russian State Vocational Pedagogical University, Yekaterinburg, Russia.

Article submitted 2020-09-11. Resubmitted 2021-01-25. Final acceptance 2021-01-27. Final version published as submitted by the authors. 